\title{
Effect of sodium hydroxide pretreatment on released sugar yields from pomelo peels for biofuel production
}

\author{
Chaichana Chatkaew ${ }^{l}$, Elizabeth Jayex Panakkal $^{2}$, Wawat Rodiahwati $^{3}$, Suchata Kirdponpattara ${ }^{1,4}$, Santi Chuetor ${ }^{1,4}$, \\ Malinee Sriariyanun ${ }^{2,4 *}$, Kraipat Cheenkachorn ${ }^{1,4 *}$ \\ ${ }^{1}$ Department of Chemical Engineering (ChE) Faculty of Engineering, King Mongkut's University of Technology North \\ Bangkok (KMUTNB), Bangkok, Thailand \\ ${ }^{2}$ Department of Chemical and Process Engineering, The Sirindhorn International Thai-German Graduate School of \\ Engineering (TGGS), King Mongkut's University of Technology North Bangkok (KMUTNB), Bangkok, Thailand \\ ${ }^{3}$ Department of Chemistry, University of New England: Armidale, New South Wales, Australia \\ ${ }^{4}$ Biorefinery and Process Automation Engineering Center (BPAEC), King Mongkut's University of Technology North \\ Bangkok (KMUTNB), Bangkok, Thailand
}

\begin{abstract}
Most of the agricultural wastes in developing countries are disposed of by on-site combustion leading to unmanaged environmental pollutions. Conversion of agricultural wastes to value-added products, such as bioethanol and biogas, is a promising method to reduce agro-waste after harvesting seasons. In this study, Citrus maxima peels (Pomelo peels) was selected to be converted to reducing sugars, which could be a raw material to produce other value-added products. To promote enzymatic hydrolysis reactions, pomelo peels were pretreated with sodium hydroxide by variations of three pretreatment parameters, including temperature $\left(50-100{ }^{\circ} \mathrm{C}\right)$, time $(0.5-6 \mathrm{~h})$, and concentration of $\mathrm{NaOH}(0.5-3.0 \mathrm{M})$. Box-Behnken design (BBD) was applied in Response Surface Methodology (RSM) to determine the optimized pretreatment conditions and to find the relationship between pretreatment factors and reducing sugar yields. The predicted optimal pretreatment condition was determined to be at $94.28{ }^{\circ} \mathrm{C}, 4.5 \mathrm{~h}, 2.17 \mathrm{M}$ with reducing sugar yield of $98.9 \mathrm{mg} / \mathrm{g}$ of dried pomelo peels. The results clearly showed that reducing sugar yields obtained from pretreated pomelo peels were 1.87 folds higher than untreated biomass $(52.81 \mathrm{mg} / \mathrm{g}$ of pomelo peels). Therefore, this study demonstrated the potential of pomelo peels to be used as an alternative raw material for value-added products rather than being a landfill or causal agent of pollution.
\end{abstract}

Keywords: Sodium hydroxide, Pretreatment, Enzymatic saccharification, Biorefinery, Biofuels

\section{INTRODUCTION}

Energy consumption has increased in the past decade across the globe. An increase in population rate along with industrial development has led to more energy consumption than in the past years. Energy production using non-renewable sources is insufficient to meet the rising energy demand. This has led to an increase in the research on renewable energy produced from hydropower, solar energy, wind power, and biomass. Many researchers have shifted their focus to biomass for energy production since it is widely available [1].

Thailand is a country rich in agricultural resources and produces a large amount of agricultural waste, such as straw, rice husk, coconut shell, sawdust, leaves, bark, fruit husk, corncob, and bagasse, etc. According to the data in 2013, Thailand produced 62 million tons of biomass per year, which had the potential to generate 13,348 thousand tons of crude oil [1]. Statistic data show the possibility of utilizing agricultural waste biomass for energy production. For instance, fruit peels from canned fruit factories could be utilized to produce biogas or can be processed into fertilizers or animal feeds. Currently, most of the residual biomass after processing in the industry is either landfilled or incinerated, which causes fine particle release with serious health and environmental concerns. Instead of this, residual biomass could be used to generate renewable energy for local use. This not only provides health benefits for people but also reduces environmental pollution [2].

Biomass materials, such as agricultural processed fruit peels, are mainly composed of lignocellulose materials. Lignocellulose is a complex material with a rigid structure. Lignocellulose is composed of 3 mains components, namely cellulose, hemicellulose, and lignin $[3,4]$. Cellulose is the main component, which is a homopolymer of glucose connected with $\beta-1,4$ linkages to form a long polymeric chain. Hemicellulose is a heteropolymer composed of repeated units of pentoses and hexoses. Lignin is an aromatic polymer that provides the rigidity for biomass. Each plant material has a varying amount of these components depending on its species, growth stage, and climate [5-7]. These components are arranged in a specific manner in the biomass to make it rigid and recalcitrant. The rigid

Corresponding author: macintous@gmail.com, kraipat@gmail.com 
nature of biomass greatly hinders the activity of enzymes or microorganisms to degrade biomass to produce energy. Therfore, a preliminary process to facilitate the disintegration of biomass, before its utilization is necessary.

In general, there are four important steps in bioenergy production, namely the pretreatment process, followed by hydrolysis, fermentation, and bioenergy extraction $[8,9]$. The pretreatment process is conducted to make biomass become vulnerable to enzyme activity. Pretreatment can be done in several ways, such as physical pretreatment )milling or grinding( [10-11], chemical pretreatment )alkali, dilute acid, oxidizing agents and organic solvents, ionic liquid( [12-20], biological pretreatment [21-24] and, physicochemical pretreatment $[10,11]$. Each method has its advantages and disadvantages. However, these pretreatment methods can increase porosity and surface area to the biomass structure [25]. This provides more surface area for the enzyme to react and increases the hydrolysis efficiency by increasing sugar yield at a reduced cost of enzyme for cellulose digestion [26]. Chemical pretreatment using acid helps in the digestion of hemicellulose and lignin to produce high sugar yield and generate inhibitors or furfural [7]. Whereas, alkaline pretreatment, using solutions such as sodium hydroxide, calcium hydroxide, and ammonia helps in the removal of lignin and some amount of hemicellulose. Pretreatment using these chemicals can cause degradation of ester and glycosidic side chains causing the cellulose to swell. This also helps in decreasing crystallinity and polymerization thereby increasing internal surface area by destroying the lignin structures [27]. Pretreatment is followed by intensive washing to remove any trapped impurities in the solids after pretreatment [28]. This can enhance the efficiency of the enzyme in the hydrolysis process [29] and thereby increases the yield of required products, such as bioethanol [26].

In this research, pomelo peels was targeted in our investigation in the production of fermentable sugars, which could subsequently be converted to value-added products or biofuels. To improve the efficiency of enzymatic saccharification of pomelo peels, the pretreatment process with sodium hydroxide was optimized based on Response Surface Methodology (RSM) with Box-Behnken design (BBD). The maximum amount of sugars produced from this work could be used as critical data for process design in the biorefining process of lignocellulosic biomass.

\section{Material and methods.}

\subsection{Raw materials}

Pomelo peels were obtained from a local market in Nonthaburi province in Thailand. Pomelo peels were dried at $60{ }^{\circ} \mathrm{C}$ for $12 \mathrm{~h}$. In hot air oven to remove moisture from them. After drying, it was cut by using house blender thoroughly and particle sizes were screened through a 20 mesh-sized aluminum sieve to obtain sample consistency. The biomass was stored in a sealed plastic bag at room temperature until further use.

CelluClast 1.5 L from Trichoderma reesei was purchased from Sigma-Aldrich (aqueous solution 700 units / g), $\beta$-glucosidase was obtained from Megazyme, Sodium hydroxide $(\mathrm{NaOH})$, and other analytical reagents were purchased from Alex Fincohem (Univar).

\subsection{Alkaline pretreatment}

A pretreatment was carried out by immersing $5 \mathrm{~g}$ of pomelo peels in $50 \mathrm{ml}$ of $\mathrm{NaOH}$ solution at a solids loading of $10 \%$. A treatment was performed in hot airoven using varied $\mathrm{NaOH}$ concentration $(0.5$ to $3 \mathrm{M})$, temperature $\left(70\right.$ to $100^{\circ} \mathrm{C}$ ) and time ( 1 to 24 hours) to preliminarily find the boundary of testing factors. After pretreatment, the solid residues were removed from the liquid fraction by filtration with Whatman No. 1 filter paper. The solid residues were further washed with distilled water until neutral $\mathrm{pH}$. The solids were dried in a hot-air oven at $60{ }^{\circ} \mathrm{C}$ for 8 hours. Pretreated samples were stored in a desiccator before proceeding to enzymatic saccharification.

\subsection{RSM Experiment design}

To determine the optimal pretreatment condition for producing maximum sugar yield (Y), BBD of RSM was selected. RSM experiments were designed with 3 pretreatment factors, namely pretreatment temperature $\left(\mathrm{X}_{1}\right)$, Pretreatment time $\left(\mathrm{X}_{2}\right)$, and $\mathrm{NaOH}$ Concentration $\left(X_{3}\right)$. Pretreatment was carried out at varied $\mathrm{NaOH}$ concentrations of $0.5-3 \mathrm{M}$, the temperature of $50-100{ }^{\circ} \mathrm{C}$, and time of 0.5-6 h. Each of these factors was set at three different levels $-1,0$, and +1 (Table 1 ). A total of 17 runs were performed by varying conditions of pretreatment factors as in Table 2. The pretreated biomass was further hydrolyzed by the enzyme to determine the reducing sugar yield. The RSM experiments were design and experimental data were analyzed by using Design Expert version 7.0.0 software.

Table 1. Independent variable factors in pretreatment condition of pomelo peels on RSM.

\begin{tabular}{|l|c|c|c|c|}
\hline \multirow{2}{*}{$\begin{array}{c}\text { Independent } \\
\text { variable factors }\end{array}$} & Coded & \multicolumn{3}{|c|}{ Levels } \\
\cline { 3 - 5 } & symbols & $\mathbf{- 1}$ & $\mathbf{0}$ & $\mathbf{+ 1}$ \\
\hline Temperature $\left({ }^{\circ} \mathrm{C}\right)$ & $\mathrm{X}_{1}$ & 50 & 75 & 100 \\
\hline Time $(\mathrm{h})$ & $\mathrm{X}_{2}$ & 0.50 & 3.25 & 6 \\
\hline Concentration $(\%)$ & $\mathrm{X}_{3}$ & 0.50 & 1.75 & 3 \\
\hline
\end{tabular}

\subsection{Enzymatic hydrolysis}

Untreated and pretreated pomelo peels were enzymatic hydrolyzed by commercial cellulase. The hydrolysis reaction was carried out using $0.1 \mathrm{~g}$ biomass in $4 \mathrm{ml}$ of hydrolysis buffer (containing $50 \mathrm{mM}$ citrate buffer, $40 \mu \mathrm{l}$ of $2 \mathrm{M}$ sodium azide, $35 \mu \mathrm{l}$ of CelluClast $1.5 \mathrm{~L}$, and $10 \mu \mathrm{l}$ of $\beta$-glucosidase enzyme). The reaction mixture was incubated at $50{ }^{\circ} \mathrm{C}, 150 \mathrm{rpm}$ for 72 hours. The reaction was stopped by incubating the reaction mixture at $100^{\circ} \mathrm{C}$ for 10 minutes. Biomass hydrolysates were harvested by 
centrifugation at $10,000 \mathrm{~g}$ for 5 minutes. The supernatant was used to analyze for reducing sugar concentration after enzymatic hydrolysis.

Table 2. RSM experimental design for $\mathrm{NaOH}$ pretreatment of pomelo peels

\begin{tabular}{|c|c|c|c|c|}
\hline \multirow[t]{2}{*}{ Run } & \multicolumn{3}{|c|}{ Pretreatment condition } & \multirow{2}{*}{$\begin{array}{c}\text { Reducing } \\
\text { sugar } \\
\text { (g/100g } \\
\text { biomass) }\end{array}$} \\
\hline & $\begin{array}{c}\mathrm{X}_{1}: \\
\text { Temperature } \\
\left({ }^{\circ} \mathrm{C}\right)\end{array}$ & $\begin{array}{c}\mathrm{X}_{2}: \\
\text { Time } \\
\text { (h) }\end{array}$ & $\begin{array}{c}\mathrm{X}_{3}: \\
\text { Concentration } \\
\text { (M) }\end{array}$ & \\
\hline 1 & 100 & 3.25 & 0.5 & 56.80 \\
\hline 2 & 50 & 6 & 1.75 & 43.44 \\
\hline 3 & 75 & 0.5 & 0.5 & 37.85 \\
\hline 4 & 100 & 3.25 & 3 & 97.76 \\
\hline 5 & 50 & 3.25 & 3 & 47.07 \\
\hline 6 & 75 & 0.5 & 3 & 41.69 \\
\hline 7 & 75 & 3.25 & 1.75 & 75.04 \\
\hline 8 & 50 & 0.5 & 1.75 & 40.44 \\
\hline 9 & 100 & 0.5 & 1.75 & 45.05 \\
\hline 10 & 75 & 3.25 & 1.75 & 79.68 \\
\hline 11 & 75 & 6 & 3 & 98.15 \\
\hline 12 & 100 & 6 & 1.75 & 91.31 \\
\hline 13 & 75 & 6 & 0.5 & 57.96 \\
\hline 14 & 75 & 3.25 & 1.75 & 78.73 \\
\hline 15 & 50 & 3.25 & 0.5 & 29.94 \\
\hline 16 & 75 & 3.25 & 1.75 & 80.27 \\
\hline 17 & 75 & 3.25 & 1.75 & 80.84 \\
\hline
\end{tabular}

\subsection{Analysis of reducing sugar}

The reducing sugar concentration was analyzed by the dinitrosalicylic acid (DNS) method [30]. Briefly, $50 \mathrm{~mL}$ of supernatant from enzymatic hydrolysis reaction was mixed with $150 \mathrm{~mL}$ of DNS solution. The mixture was incubated at $95^{\circ} \mathrm{C}$ in a water bath for 5 minutes. The mixture was incubated on ice for 5 minutes. After incubation, $1 \mathrm{~mL}$ of distilled water was added to the mixture and it was mixed well with a vortex shaker. The reducing sugar concentration was measured using a UV / VIS spectrophotometer at $540 \mathrm{~nm}$. The concentration of reducing sugar was calculated based on a glucose standard curve (Figure 1). The effects of various pretreatment conditions on reducing sugar concentration were statistically analyzed by ANOVA.

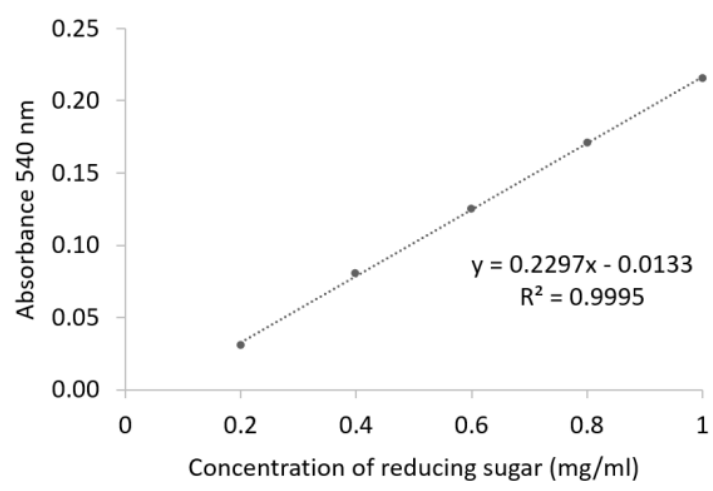

Fig. 1. Standard glucose curve for DNS method.

\section{Result and discussion}

\subsection{Alkaline pretreatment of Pomelo peels}

An alkaline pretreatment of pomelo peels was carried out to understand the range of pretreatment factors to be used in the RSM study for optimization of pretreatment conditions based on the sugar yield. Initially, pomelo peels was pretreated varying pretreatment temperature from 70 to $100{ }^{\circ} \mathrm{C}$ while keeping $\mathrm{NaOH}$ concentration and pretreatment time constant at $2 \mathrm{M}$ and 1 hour respectively. The results clearly show that the yield of reducing sugar has increased from $52.81 \mathrm{~g}$ to $91.01 \mathrm{~g} /$ $100 \mathrm{~g}$ pomelo peels when the pretreatment temperature was increased (Figure 2a).

(a)

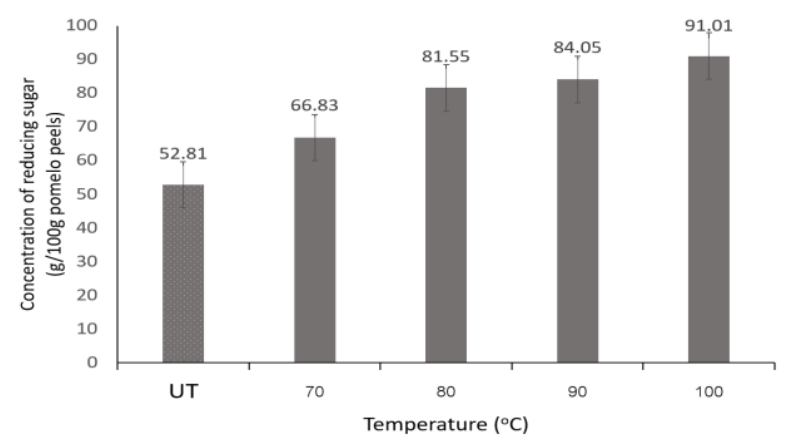

(b)

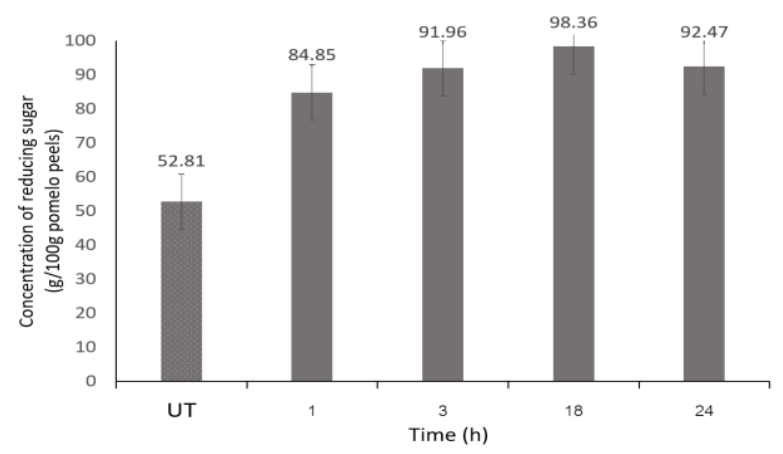

(c)

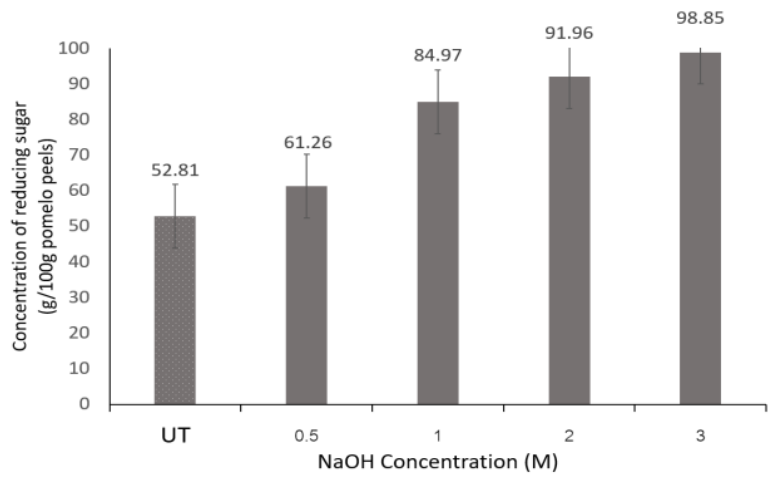

Fig. 2. Effect of pretreatment temperature, time and $\mathrm{NaOH}$ concentration on the enzymatic hydrolysis of Pomelo peels. (A) The pretreatment was using $2 \mathrm{M}$ of $\mathrm{NaOH}$ for 1 hour, (B) The pretreatment was using $2 \mathrm{M}$ of $\mathrm{NaOH}$ at $80^{\circ} \mathrm{C}$ and (C) The pretreatment were conducted at $80^{\circ} \mathrm{C}$ for 3 hours. 
In comparison with the untreated biomass, there was a 1.72-fold increase in the sugar yield when pretreated at $100^{\circ} \mathrm{C}$. Similarly, when the pretreatment was carried out by varying the $\mathrm{NaOH}$ concentration from 0.5 to $3 \mathrm{M}$, at $80{ }^{\circ} \mathrm{C}$ for 3 hours, the result showed that the reducing sugar yield increased with the increasing $\mathrm{NaOH}$ concentration (Figure 2b). A maximum sugar yield of $99.52 \mathrm{~g} / 100 \mathrm{~g}$ of biomass was obtained at $3 \mathrm{M}$ $\mathrm{NaOH}$ concentration, which is 1.88 times more than untreated pomelo peels. Unlike this, when the pretreatment was performed by varying time from 1-24 hours, with $2 \mathrm{M} \mathrm{NaOH}$ at $80{ }^{\circ} \mathrm{C}$, the reducing sugar yield increased up to a certain pretreatment time, after that the yield was reduced (Figure $2 \mathrm{c}$ ). The reducing sugar yield increased from $52.81 \mathrm{~g} / 100 \mathrm{~g}$ biomass to $98.36 \mathrm{~g} / 100 \mathrm{~g}$ pomelo peels by 18 hours of pretreatment. However, when the pretreatment time was further extended to 24 hours, the reducing sugar yield decreased to $92.47 \mathrm{~g} / 100$ $\mathrm{g}$ pomelo peels. This could be possibly due to the destruction of the internal structure of the biomass caused by the long pretreatment time. Also, the sugar yield did not show much variation when the pretreatment time was varied from 3 hours (91.96 g/ $100 \mathrm{~g}$ biomass) to 18 hours ( $98.36 \mathrm{~g} / 100 \mathrm{~g}$ biomass). Hence, to reduce the pretreatment cost and time, the time range for pretreatment at the RSM study was chosen between 0.5 and 6 hours.

\subsection{RSM design and experimental testing}

The RSM is considered an efficient method to design and conduct experiments to achieve the optimal state in the production process. RSM evaluates the effects of individual independent variables and their interactions with RSM-dependent variables and also helps to reduce the number of experimental trials. It is widely used to reduce the time and cost of the experiment. In addition to this, RSM can also predict results and can create surface models under different conditions of the independent variables. Several studies have applied RSM to improve the efficacy of their studies [31-34].

In this study, RSM created the BBD matrix with 3 levels of testing: low $(-1)$, mid $(0)$, and high $(+1)$ for three factors used for the pretreatment (pretreatment time, pretreatment temperature, and $\mathrm{NaOH}$ concentration). A total of 17 runs were conducted. The statistical analysis was performed using Design-Expert software (ver. 7.0.0) throughout this research. The experimental data were used to find the experimental coefficient $(\beta)$ using the least-squares method. In addition to this, the second-order model was generated from the experimental data. The optimum pretreatment conditions were determined based on the highest yield of reducing sugar from the multiple regression analysis of the second-order model. The correlation of the secondorder model was assessed by determination of the coefficient $\left(\mathrm{R}^{2}\right)$, the significance of the test condition in ANOVA, and the lack of fit, which is generally considered significant when the $\mathrm{R}^{2}$ value is greater than 0.9 [31-34]. In this paper, $\mathrm{R}^{2}$ value of model was 0.9396 , which indicated the lower variance during the experiment and reliability of the model. ANOVA was further conducted to determine the importance of the second-order model (Table 3).

Table 3. ANOVA analysis of the second-order model obtained from RSM experiments.

\begin{tabular}{|c|c|c|c|c|c|}
\hline Source & $\begin{array}{c}\text { Sum of } \\
\text { Squares }\end{array}$ & df & $\begin{array}{c}\text { Mean } \\
\text { Squares }\end{array}$ & $\begin{array}{c}\text { F } \\
\text { Value }\end{array}$ & $\begin{array}{c}\text { P- } \\
\text { value } \\
\text { Prob }> \\
\text { F }\end{array}$ \\
\hline Model & 8018.51 & 9 & 890.95 & 28.65 & $\begin{array}{c}< \\
0.0001\end{array}$ \\
\hline A-Time & 2113.48 & 1 & 2113.48 & 67.96 & $\begin{array}{c}< \\
0.0001\end{array}$ \\
\hline B-Time & 1979.15 & 1 & 1979.15 & 63.64 & $<$ \\
\hline C-Conc & 1303.56 & 1 & 1303.56 & 41.92 & 0.0001 \\
\hline $\mathrm{A}^{2}$ & 651.18 & 1 & 651.18 & 20.94 & 0.0026 \\
\hline $\mathrm{B}^{2}$ & 548.74 & 1 & 548.74 & 17.65 & 0.0040 \\
\hline $\mathrm{C}^{2}$ & 310.22 & 1 & 310.22 & 9.98 & 0.0160 \\
\hline Residual & 217.68 & 7 & 31.10 & & \\
\hline $\begin{array}{c}\text { Lack of } \\
\text { Fit }\end{array}$ & 196.5 & 3 & 65.50 & 12.37 & 0.0172 \\
\hline $\begin{array}{c}\text { Pure } \\
\text { Error }\end{array}$ & 21.18 & 4 & 5.29 & & \\
\hline Cor Total & 8236.19 & 16 & & & \\
\hline
\end{tabular}

The ANOVA analysis of the model was found to have an $F$ value of 28.65 with statistical significance ( $p$ $<0.05$ ) and a $0.01 \%$ chance of the model F-value noise. Moreover, pretreatment temperature, pretreatment time, $\mathrm{NaOH}$ concentration were also significant pretreatment factors according to ANOVA analysis. The lack of fit is 12.37 which was also considered significant and has a $1.72 \%$ chance of noise. However, according to the data we have found that there was a small chance that the model will not fit and distributes anomalies. According to the ANOVA analysis above, it was estimated that all three parameters : pretreatment temperature, pretreatment time, $\mathrm{NaOH}$ Concentration affected the reducing sugar production after pretreatment of pomelo peels. Other studies have also used such parameters as L. Kim et al [35] performed alkaline pretreatment of Rice straw by using $\mathrm{NaOH}$ under various conditions of time, temperature and $\mathrm{NaOH}$ concentration to find a correlation between reducing sugar content and pretreatment parameters, In addition, P. Amnuaycheewa et. al. [36] performed acid pretreatment of Napier grass by using HCL under various conditions of time, temperature and HCL concentration to reported a similar correlation between reducing sugar contents and pretreatment parameters, so it was found that these parameters were related to reducing sugar content.

\subsection{Effect of pretreatment parameters on the enzymatic saccharification on mathematical models}

The impact of each factor, pretreatment temperature, pretreatment time, $\mathrm{NaOH}$ Concentration on the response of the curve was analyzed based on the concentration of 
reducing sugar (Figure 3 ). The model also analyzed the effect of the interaction between independent variables (pretreatment factors) in the form of a three-dimensional contour plot. The data showed that the yield of reducing sugar increased as the pretreatment temperature (Figure 4a), pretreatment time (Figure 4b), and $\mathrm{NaOH}$ concentration increased (Figure 4c). This implied that all three parameters affected the sugar yield. The more severe pretreatment conditions could lead to the swelling in the cellulose structure, leading to an increase in the surface area. This provided more accessibility for the enzyme to cellulose leading to enhanced sugar production.

(a)

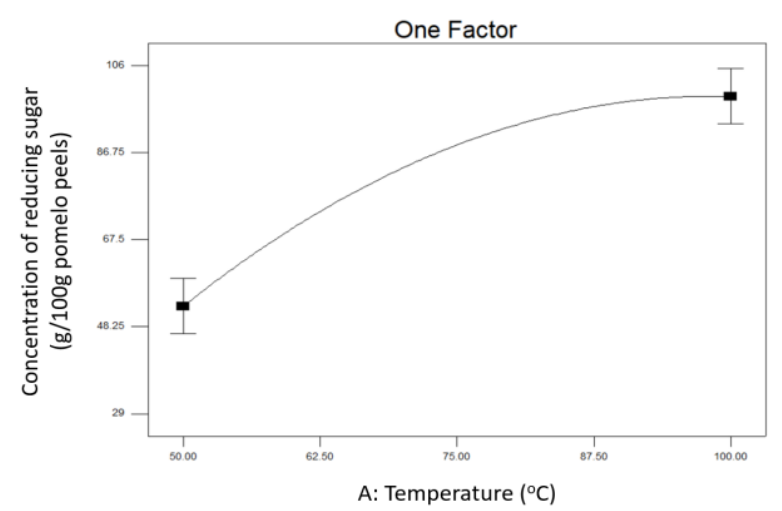

(b)

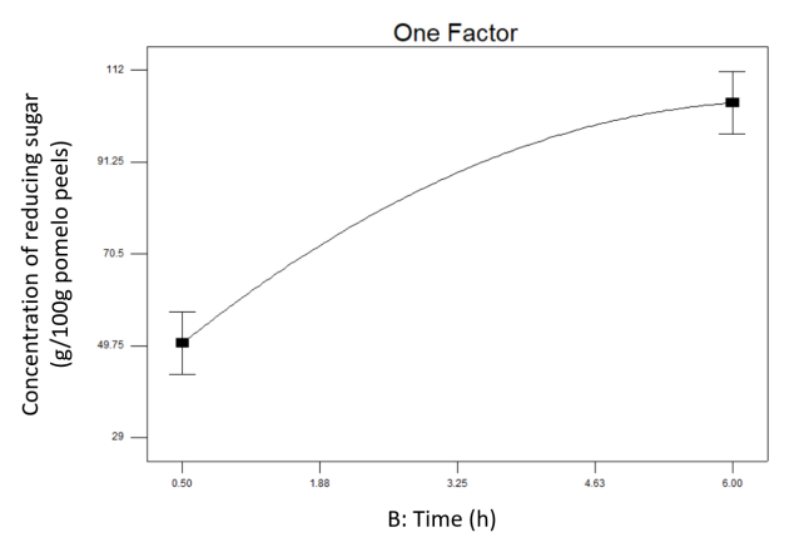

(c)

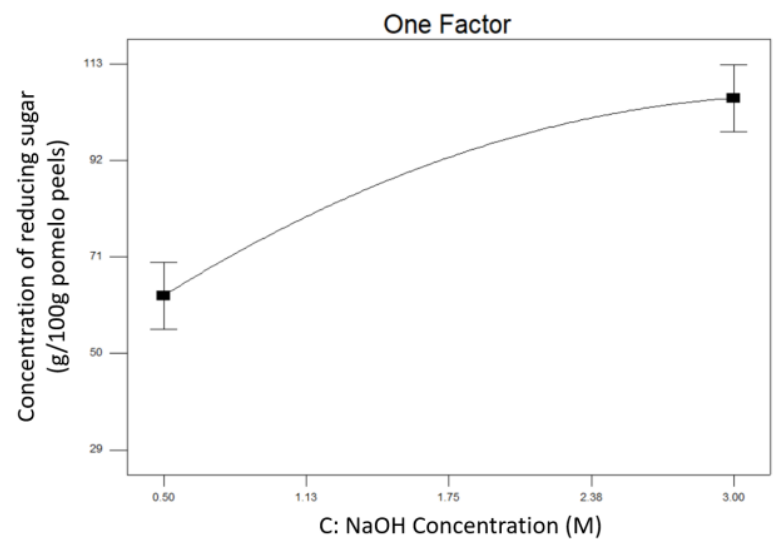

Fig. 3. Relationship between each pretreatment factor, (A) pretreatment temperature $\left({ }^{\circ} \mathrm{C}\right),(\mathrm{B})$ pretreatment time $(\mathrm{h}),(\mathrm{C})$ $\mathrm{NaOH}$ concentration $(\mathrm{M})$ and $\mathrm{Y}$-axis is concentration of reducing sugar $(\mathrm{g} / 100 \mathrm{~g}$ pomelo peels) (a)

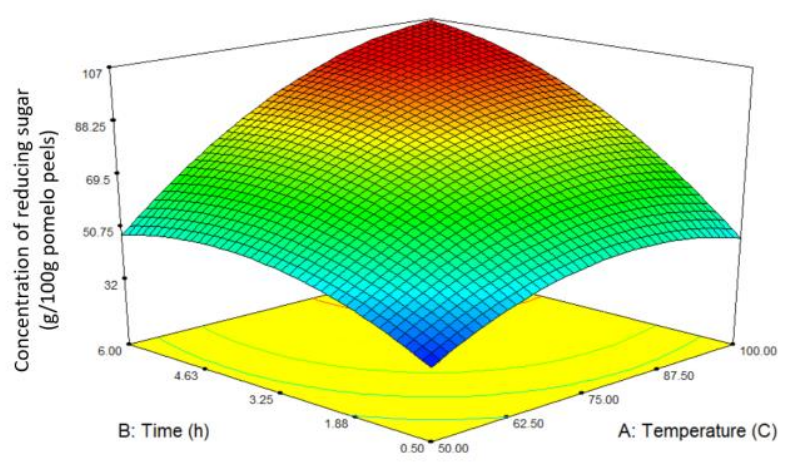

(b)

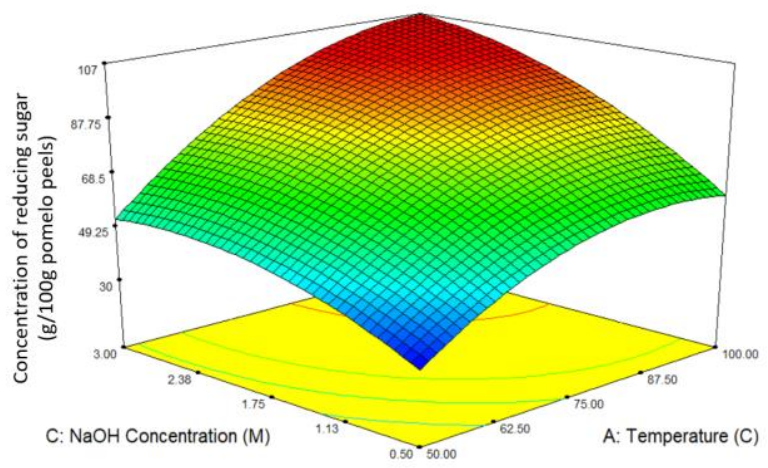

(c)

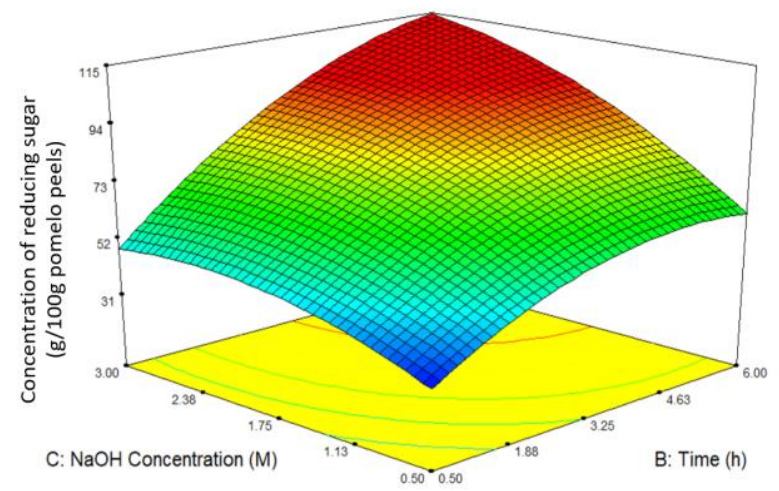

Fig. 4. Response surface plot represents the effects of pretreatment factors on reducing sugar yield $(\mathrm{g} / 100 \mathrm{~g}$ pomelo peels). (A) pretreatment temperature vs. pretreatment time, (B) pretreatment temperature vs $\mathrm{NaOH}$ concentration and (C) pretreatment time vs $\mathrm{NaOH}$ concentration

ANOVA analysis could simulate a model and predict optimal parameters for the pretreatment. The mathematical model suggested pretreatment using 2.17 $\mathrm{M} \mathrm{NaOH}$ at $94.28{ }^{\circ} \mathrm{C}$, for 4.5 hours as the optimal pretreatment conditions for pretreating Pomelo peels to yield maximum sugar yield. (Table 4). The model also predicted that the optimal pretreatment condition could yield $98.9 \mathrm{mg}$ reducing sugar per gram of pomelo peels. To confirm the reliability of this model, pretreatment was conducted again at the predicted optimal pretreatment conditions. It could yield $99.1 \mathrm{mg}$ reducing sugar per gram pomelo peels with only $0.2 \%$ error from the predicted value. When comparing the yield of reducing sugar, it could be deduced that the model from ANOVA prediction was highly accurate 
Table 4. Mathematical models and optimal pretreatment condition obtained from RSM experiment.

\begin{tabular}{|c|c|c|}
\hline \multicolumn{3}{|c|}{$\begin{array}{l}\text { Mathematical Model } \\
\text { Reducing sugar }=-72.59982+2.78992 \times \text { Temp }-0.89290 \times \\
\text { Time }+6.54922 \times \text { Conc }+0.15731 * \text { Temp } * \text { Time }+0.19064 * \\
\text { Temp * Conc }+2.64364 \times \text { Time } \times \text { Conc }-0.019898 \times \text { Temp }{ }^{2}- \\
1.50955 * \text { Time }^{2}-5.49344 \times \text { Conc }^{2}\end{array}$} \\
\hline \multicolumn{3}{|c|}{ Optimal pretreatment parameter } \\
\hline Temperature $\left({ }^{\circ} \mathrm{C}\right)$ & Time (h) & $\begin{array}{c}\mathrm{NaOH} \\
\text { Concentration(M) }\end{array}$ \\
\hline 94.28 & 4.5 & 2.17 \\
\hline $\begin{array}{c}\text { Predicted } \\
\text { Concentration of } \\
\text { sugar }(\mathrm{g} / 100 \mathrm{~g} \\
\text { pomelo peels })\end{array}$ & $\begin{array}{l}\text { Experimental } \\
\text { Concentration } \\
\text { of sugar } \\
\text { (g/100g pomelo } \\
\text { peels) }\end{array}$ & Difference $(\%)$ \\
\hline 98.90 & 99.10 & 0.2 \\
\hline
\end{tabular}

\section{Conclusion}

The study was conducted to achieve maximum yield of reducing sugar from optimally pretreated pomelo peels and these sugars could be further converted to products such as biogas, bioethanol, etc. In this research, the optimization of pretreatment conditions was carried out using the RSM model. The preliminary alkaline pretreatment studies could help us in determining the range of pretreatment factors to be used in the RSM model. BBD of RSM was applied to design the experiments with various pretreatment conditions by varying $\mathrm{NaOH}$ concentration, pretreatment temperature, and pretreatment time. The BBD design along with the ANOVA analysis predicted $\mathrm{NaOH}$ concentration of $2.17 \mathrm{M}$, pretreatment temperature of $94.28{ }^{\circ} \mathrm{C}$, and pretreatment time of 4.5 hours as optimal pretreatment condition, which could yield of reducing sugars of 98.9 $\mathrm{mg} / \mathrm{g}$ of pomelo peels. This implied a 1.87 fold increase in sugar yield obtained from pretreated biomass compared to untreated biomass. This study demonstrated the potential of pomelo peels to be used as feedstock in the biorefining process. Also, it provided an alternative way to reduce agriculture waste and air pollution.

\section{Acknowledgement}

The authors would like to thank King Mongkut's University of Technology, North Bangkok (Research Grant No. KMUTNB-BasicR-64-37, KMUTNB-PHD64-02) for financial support of this work.

\section{References}

1. Ministry of Energy Annual Report, Biomass production.http://biomass.dede.go.th/biomass web/i ndex.html.

2. YS. Cheng, P. Mutrakulcharoen, S. Chuetor, K. Cheenkachorn, P. Tantayotai, EJ. Panakkal, M.
Sriariyanun, Recent situation and progress in biorefining process of lignocellulosic biomass: toward green economy, Applied Science and Engineering Progress, 13,4(2020): 299-311.

3. EJ. Panakkal, M Sriariyanun, J. Ratanapoompinyo P. Yasurin, K. Cheenkachorn, W. Rodiahwati, P. Tantayotai, Influence of Sulfuric Acid Pretreatment and Inhibitor of Sugarcane Bagasse on the Production of Fermentable Sugar and Ethanol, Applied Science and Engineering Progress, 15,1(2022)

4. M. Sriariyanun, K. Kitsubthawee, Trends in Lignocellulosic Biorefinery for Production of Value-added Biochemicals, Applied Science and Engineering Progress. 13(4), (2020): 283-284.

5. H. Chen, J. Liu, X. Chang, D. Chen, Y. Xue, P. Liu, H. Lin and S. Han, A review on the pretreatment of lignocellulose for high-value chemicals., Fuel Processing Technology. 160, (2017): 196-206.

6. M. Sriariyanun, JH. Heitz, P. Yasurin, S. Asavasanti, P. Tantayotai, Itaconic acid: A promising and sustainable platform chemical, Applied Science and Engineering Progress. 12(2), (2019) : 75-82.

7. P. Rachmontree, T. Douzou, K. Cheenkachorn, M. Sriariyanun, Furfural : A sustainable platform chemical and fuel, Applied Science and Engineering Progress. 13(1), (2020): : 3-10.

8. MP. Gundupalli, YS. Cheng, S. Chuetor, D. Bhattacharyya, M. Sriariyanun. Effect of Dewaxing on saccharification and ethanol production from different lignocellulosic biomass. Bioresource Technology. 125596.

9. R. Akkharasinphonrat, T. Douzou, M. Sriariyanun, Development of ionic liquid utilization in biorefinery process of lignocellulosic biomass, King Mongkut's University of Technology North Bangkok International Journal of Applied Science and Technology, 10,2 (2017): 89-96

10. W. Rodiahwati and M. Sriariyanun, Lignocellulosic Biomass to Biofuel Production: Integration of Chemical and Extrusion )Screw Press( Pretreatment, KMUTNB International Journal of Applied Science and Technology., 9)4(, (2016): 289-298.

11. S. Chuetor, T. Ruiz, A. Barakat, N. Laosiripojana, V. Champreda, M. Sriariyanun, Evaluation of rice straw biopowder from alkaline-mechanical pretreatment by hydro-textural approach, Bioresource Technology. 323, (2021)

12. M. Sriariyanun, Q. Yan, I. Nowik, K. Cheenkachorn, T. Phusantisampan, M. Modigell, Efficient pretreatment of rice straw by combination of screw press and ionic liquid to enhance enzymatic hydrolysis, Kasetsart Journal (Natural Science(, 49, (2015): 146-154.

13. K. Cheenkachorn, T. Douzou, S. Roddecha, P. Tantayotai, and M. Sriariyanun, Enzymatic saccharification of rice straw under influence of 
recycled ionic liquid pretreatments, Energy Procedia. 100, )2016(: 160-165.

14. K. Rattanaporn, S. Roddecha, M. Sriariyanun, K. Cheenkachorn, Improving saccharification of oil palm shell by acetic acid pretreatment for biofuel production, Energy Procedia, 141C, )2017(: 146149.

15. K. Rattanaporn, P. Tantayotai, T. Phusantisampan, P. Pornwongthong, M. Sriariyanun, Organic acid pretreatment of oil palm trunk: effect on enzymatic saccharification and ethanol production, Bioprocess and Biosystem Engineering, 41, (2018): 467-477.

16. MP. Gundupalli, A. Sahithi, YS. Cheng, P. Tantayotai, M. Sriariyanun. 2021. Differential effects of inorganic salts on cellulase kinetics in enzymatic saccharification of cellulose and lignocellulosic biomass. Bioprocess and Biosystems Engineering. Published online. (2021).

17. A. Boontum, J. Phetsom, W. Rodiahwati, K. Kitsubthawee and T. Kuntothom, Characterization of Diluted-acid Pretreatment of Water Hyacinth, Applied Science and Engineering Progress. 12(4), (2019): 253-263.

18. YS. Cheng, ZY. Wu, M. Sriariyanun, Evaluation of Macaranga tanarius as a biomass feedstock for fermentable sugars production, Bioresource Technology. 294, (2019).

19. P. Tantayotai, K. Rattanaporn, S. Tepaamorndech, K. Cheenkachorn, M. Sriariyanun "Analysis of an ionic liquid and salt tolerant microbial consortium which is useful for enhancement of enzymatic hydrolysis and biogas production, Waste and Biomass Valorization, 10)6(, (2019): 1481-1491.

20. P. Tantayotai, P. Pornwongthong, C. Muenmuang, T. Phusantisampan and M. Sriariyanun, Effect of cellulase-producing microbial consortium on biogas production from lignocellulosic biomass, Energy Procedia. 141C, )2017(: 180-183.

21. M. Sriariyanun, P. Tantayotai, P. Yasurin, P. Pornwongthong, and K. Cheenkachorn, Production, purification and characterization of an ionic liquid tolerant cellulase from Bacillus sp. isolated from rice paddy field soil, Electronic Journal of Biotechnology. 19, (2016): 23-28.

22. P. Tantayotai, P. Rachmontree, W. Rodiahwati, K. Rattanaporn, M. Sriariyanun, Production of ionic liquid-tolerant cellulase produced by microbial consortium and its application in biofuel production, Energy Procedia. 100, )2016(: 155-159.

23. P. Chandranupap, P. Chandranupap, Effect of Hemicellulase Enzyme in Flotation Deinking of Laser-printed Paper, Applied Science and Engineering Progress. 14(3), (2021): 370-377.

24. R. Runajak, S. Chuetor, W. Rodiahwati, M. Sriariyanun, P. Tantayotai, and S. Phornphisutthimas, "Analysis of Microbial Consortia with High Cellulolytic Activities for Cassava Pulp Degradation, E3S Web of Conferences. 141, (2020)
25. Y. Zheng, J. Zhao, F. Xu and Y. Li, Pretreatment of lignocellulosic biomass for enhanced biogas production, Progress in Energy and Combustion Science 42, (2014):35-53

26. W. Siri-anusornsak, N. Sinbuathong, Chemical pretreatment of rice straw for a raw material in the production of renewable energy, Proceedings of 51st Kasetsart University Annual Conference: Science, Natural Resources and Environment, (2014).

27. R. Pawongrat, Pretreatment processes for enhancing the efficiency of ethanol production from lignocellulosic agricultural wastes, Veridian EJournal Science and Technology Silpakorn University, (2015).

28. C. Martin, B. Alriksson, A. Sjode, N. Nilverbrant and L.J. Jonsson, Dilute Sulfuric Acid Pretreatment of Agricultural and Agro-Industrial Residues for Ethanol Production, Applied Biochemistry and Biotechnology, (2011).

29. T. Li, Production of bioethanol from unwashedpretreated rapeseed straw at high solid loading, Chengdu Institute of Biology. Bioresource

30. G.L. Miller, Use of dinitrosalicylic acid reagent for determination of reducing sugar, Analytical Chemistry 31, (1959): 426-428.

31. S. Akkaravathasinp, P. Narataruksa, C. Prapainainar, Optimization of Semi-batch Reactive Distillation Using Response Surface Method: Case Study of Esterification of Acetic acid with Methanol in a Process Simution, Applied Science and Engineering Progress. 12(3), (2019): 209-215.

32. M. Bahadi, N. Salih, J. Salimon, D-Optimal Design Optimization for the Separation of Oleic Acid from Malaysian High Free Fatty Acid Crude Palm Oil Fatty Acids Mixture Using Urea Complex Fractionation, Applied Science and Engineering Progress. 14(2), (2021): 175-186.

33. L.K. Akula, R.K. Orauganti, D. Bhattacharyya, Treatment of Marigold Flower Processing Wastewater Using a Sequential BiologicalElectrochemical Process, Applied Science and Engineering Progress. 14(3), (2021).

34. P. Pangsri, T. Wuttipornpun, W. Songserm, Mannanase and Cellulase Enzyme Production from the Agricultural Wastes by the Bacillus subtilis P2-5 Strain, Applied Science and Engineering Progress. 14(3), (2021).

35. L. Kim and J. Han, Optimization of alkaline pretreatment conditions for enhancing glucose yield of rice straw by response surface methodology, Department of Civil and Environmental Engineering. KAIST, 373-1, (2012).

36. P. Amnuaycheewa, W. Rodiahwati, P. Sanvarinda, K. Cheenkachorn, A. Tawai and M. Sriariyanun, Effect of Organic Acid Pretreatment on Napier Grass (Pennisetum purpureum) Straw Biomass Conversion, KMUTNB International Journal of Applied Science and Technology. 10(2), (2017). 